\title{
Chiral Ion Mediated Asymmetric Chemistry
}

\author{
Jérôme Lacour*
}

\begin{abstract}
The octahedral geometry of pentavalent hexacoordinated phosphorus allows the formation of chiral anions by complexation of the central phosphorus atom with three bidentate ligands. These simple-tomake derivatives can be combined with chiral cations and often display efficient NMR chiral shift, resolving and asymmetry-inducing properties. This paper is a short review of our research efforts directed towards the development of chiral anion mediated asymmetric chemistry.
\end{abstract}

Keywords: Chiral recognition · Hexacoordinated phosphorus · Ion pairing $\cdot$ NMR .

Supramolecular chemistry

\section{Introduction}

Many chemical reactions and processes involve cationic reagents, intermediates or products. Cations are frequent intermediates along reaction pathways that react with nucleophiles to produce interesting fragments and functional groups. Cations are often Lewis acidic and numerous applications have been developed using these reagents. A large range of important biological properties are mediated by ammonium and imidazolium ions. Cations have also interesting physical properties being, for instance, among the first synthetic dyes to be developed [1]. Cations are also efficient templates for the construction of complex supramolecular arrays, such as the catenanes, knots, helicates and rotaxanes [2].

Cations can be also prostereogenic or chiral and many of the above-mentioned

${ }^{\star}$ Correspondence: Prof. J. Lacour

Université de Genève

Département de chimie organique

Quai Ernest Ansermet 30

$\mathrm{CH}-1211$ Genève 4

Tel.: +4122702 6062

Fax: +4122328 7396

E-Mail: jerome.lacour@chiorg.unige.ch

htttp://www.unige.ch/sciences/chiorg/lacour applications, reactions or processes lead to racemic molecular or supramolecular assemblies. To afford instead non-racemic or enantiopure products, and benefit from possible new applications, an asymmetric ion pairing of the cations with chiral anionic counterions can be considered - the anions behaving as asymmetric auxiliaries.

Recently, the chemistry of borate [3] and phosphate anions has been rejuvenated for exactly this purpose. In this account, we will present our efforts to develop the synthesis of novel chiral hexacoordinated phosphate anions and detail some of their asymmetric applications.

\section{Novel Chiral Hexacoordinated Phosphate Anions ...}

The octahedral geometry of pentavalent hexacoordinated phosphorus allows the formation of chiral anions $-\Delta$ and $\Lambda$ enantiomers - by complexation of the central phosphorus atom with three identical bidentate ligands. Tris(benzenediolato) phosphate anion 1 (Fig. 1), of particular interest for its easy preparation from catechol, $\mathrm{PCl}_{5}$ and an amine, is unfortunately configurationally labile in solution as an ammonium salt, due to an acid-induced racemization mechanism [4]. Previously, we were able to show that the introduction of electron-withdrawing chlorine atoms on the aromatic nuclei increases the configurational stability of the resulting tris(tetrachlorobenzene-diolato)phosphate(v) deriv- ative [5]. This $D_{3}$-symmetric anion 2, known as TRISPHAT, can be resolved by association with a chiral ammonium cation [6].

Assuming that its $D_{3}$-symmetry would not be adapted to all the possible asymmetric applications, the synthesis of $C_{2}$-symmetric hexacoordinated phosphate anions was considered; our interest being motivated by the overall efficiency of such a symmetry in asymmetric reactions or molecular recognition processes [7]. An efficient and general one-pot process was developed for the preparation of new classes of enantiopure $C_{2}$-symmetric anions - BINPHAT 3 [8], HYPHAT [9], and TARPHAT [10] - containing BINOL, hydrobenzoin and tartrate ligands respectively; all these anions being isolated as their dimethylammonium salts in good yields and chemical purity.

\section{3. ... as NMR Chiral Shift Agents}

As already mentioned, chiral cations are involved in many areas of chemistry and, unfortunately, only few methods are available to determine with precision their optical purity. In the last decades, NMR has evolved as one of the methods of choice for the measurement of the enantiomeric purity of chiral species [11]. Lanthanide reagents, which have been particularly efficient for most applications, have however been rarely used with chiral cations due to excessive line broadening and distorted baselines [12]. 
Over the past few years we could demonstrate that TRISPHAT 2 and BINPHAT 3 anions are efficient NMR chiral shift agents. They form tightly associated diastereomeric ion pairs with chiral cations and the short-range interactions that occur lead to an efficient NMR enantiodifferentiation. Well-separated signals are usually observed on the spectra of the diastereomeric salts. Cationic species as different as diquats [13], quaternary ammonium [14], phosphonium [15] thiiranium ions [16], ruthenium tris(diimine) [6a,][17] and $\left(\eta^{6}\right.$-arene)manganese [18] complexes have been analyzed with success (Fig. 2). TRISPHAT anion 2 seems to be particularly efficient with cationic metallo-organic and organometallic substrates. BINPHAT 3 has often-superior chiral shift properties than 2 when associated with organic cations. Recently, several independent reports have confirmed the efficiency of these chiral shift agents [19].

Furthermore, in collaboration with the group of Prof. Kündig (Univ. of Geneva), we were able to show that TRISPHAT can be used to determine the enantiomeric purity of ( $\eta^{6}$-arene) chromium complexes. This result broadens the field of application of 2 to neutral species [20].

\section{4. ... as Resolving Agents}

We soon discovered that the lipophilicity of the TRISPHAT anion confers to its salts an affinity for organic solvents (OL) and, once dissolved, the ion pairs do not partition in aqueous layers (AL). We immediately imagined that this uncommon property could be used to develop a simple and practical resolution procedure.

The resolution of racemic substrates by preferential extraction of one enantiomer from water into immiscible organic solvents has been well studied [21]. The extraction and the resulting selectivity arise from the preferential binding in the organic phase of one enantiomer of the substrate with a chiral lipophilic selector. Anion 2 was thus considered for the asymmetric extraction in organic layers of chiral cations, and coordination complexes in particular.

Ruthenium(II) tris(diimine) derivatives $\left(\Delta\right.$ or $\Lambda$ enantiomers, $\left[\mathrm{RuL}_{3}\right]^{2+}$ ) were selected for their ease of synthesis and high water solubility as chloride salts [22]. The extraction experiments proceeded as planned (Fig. 3) and selectivity ratios as high as 35:1 were observed for the enantiomers of the cations in the OL and AL, demonstrating without ambiguity the efficiency of the resolution procedure. An extension of this protocol was further developed for a diiron(II)

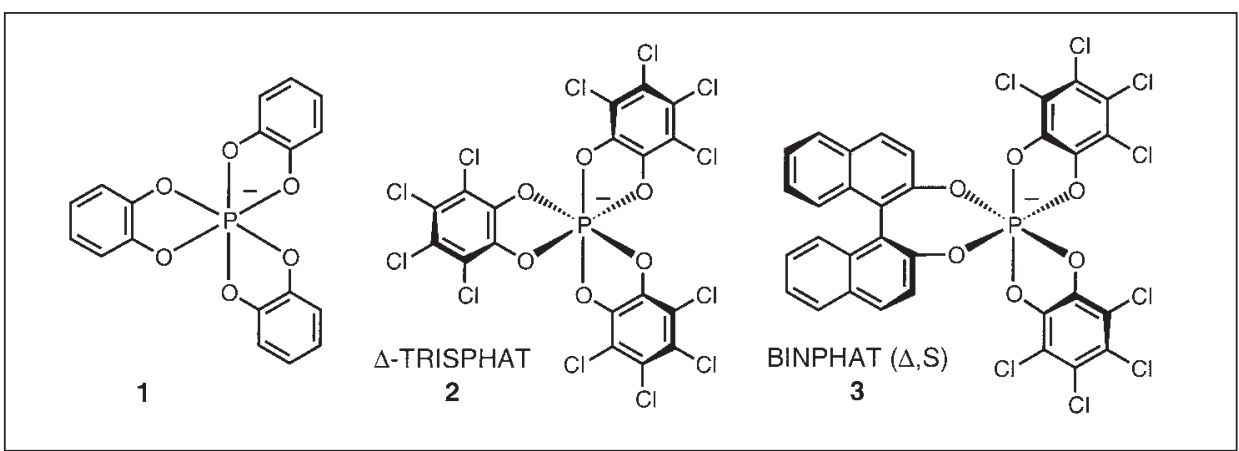

Fig. 1. Hexacoordinated phosphate anions: 1, 2 (TRISPHAT) and 3 (BINPHAT).

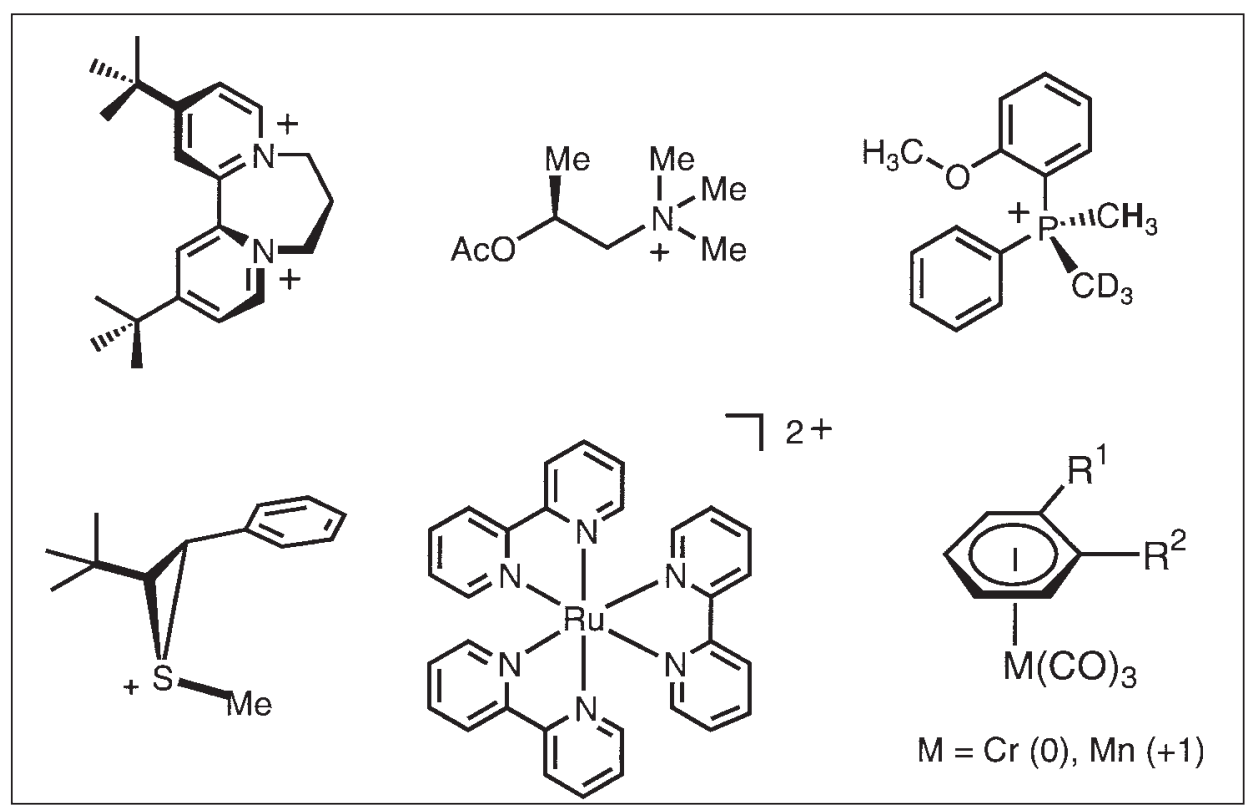

Fig. 2. Chiral cations analyzed for their enantiomeric purity with TRISPHAT or BINPHAT salts.

triple helicate and afforded in separated phases the $P$ or $M$ enantiomers of the $\left[\mathrm{Fe}_{2} \mathrm{~L}_{3}\right]^{4+}$ helix [23].

The lipophilicity of TRISPHAT anion also modifies profoundly the chromatographic properties of the cations associated with it and the resulting ion pairs are usually poorly retained on polar chromatographic phases [24]. Using enantiopure TRISPHAT anion, the chromatographic resolution of chiral cations is feasible as the

diastereomeric ion pairs often possess rather different retardation factors.

For instance, ruthenium(II) tris(diimine) complexes can be easily separated into diastereomeric homochiral $\left[\Delta-\mathrm{RuL}_{3}\right][\Delta-2]_{2}$ and heterochiral $\left[\Lambda-\mathrm{RuL}_{3}\right][\Delta-2]_{2}$ salts by column chromatography over silica gel (eluent $\mathrm{CH}_{2} \mathrm{Cl}_{2}$ ) [25]. The resolution can be also performed on preparative thin-layer chromatographic plates. The protocol was recently extended to monocationic cy-

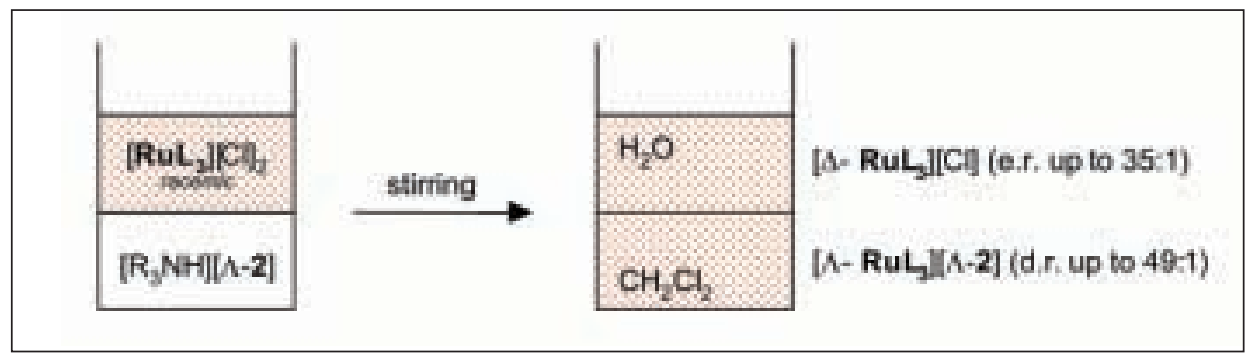

Fig. 3. Stereoselective extraction of racemic $\left[\mathrm{Ru}(\text { diimine })_{3}\right][\mathrm{Cl}]_{2}$ complexes by ammonium TRISPHAT salts, e.g. $\left[\mathrm{Bu}_{3} \mathrm{NH}\right][\Lambda-2]$. 
clometallated ruthenium complexes [26] and to a configurationally stable mononuclear iron(II) complex (Fig. 4) [27].

\section{5. ... as Asymmetry-Inducers}

Chiral compounds are sometimes configurationally stable as solids and configurationally labile in solution. When optically active samples of these derivatives are solubilized, a racemization occurs due to the free interconversion of the enantiomers in solution. To obtain these compounds in one predominant configuration over time, a possible strategy is to add stereogenic elements to their backbone; intramolecular diastereoselective interactions happen and favor one of equilibrating diastereomers [28]. If the chiral compounds are charged, an alternative strategy to control their configura- tion is to consider their asymmetric ion pairing with chiral counter-ions; intermolecular - rather than intramolecular - diastereoselective interactions then control the stereoselectivity (Pfeiffer effect) [29].

The induction of optical activity by chiral anions onto cationic racemic substrates has been previously considered [3a][30]. Unfortunately, in most of the previous examples, the extent of the asymmetric induction was determined by chiroptical measurements that gave qualitative and not quantitative information. We therefore studied the asymmetric ion pairing of configurationally labile cations with TRISPHAT and BINPHAT anions hoping that selective chiral recognition and NMR enantiodifferentiation processes would occur concomitantly allowing a precise determination of the asymmetric induction.

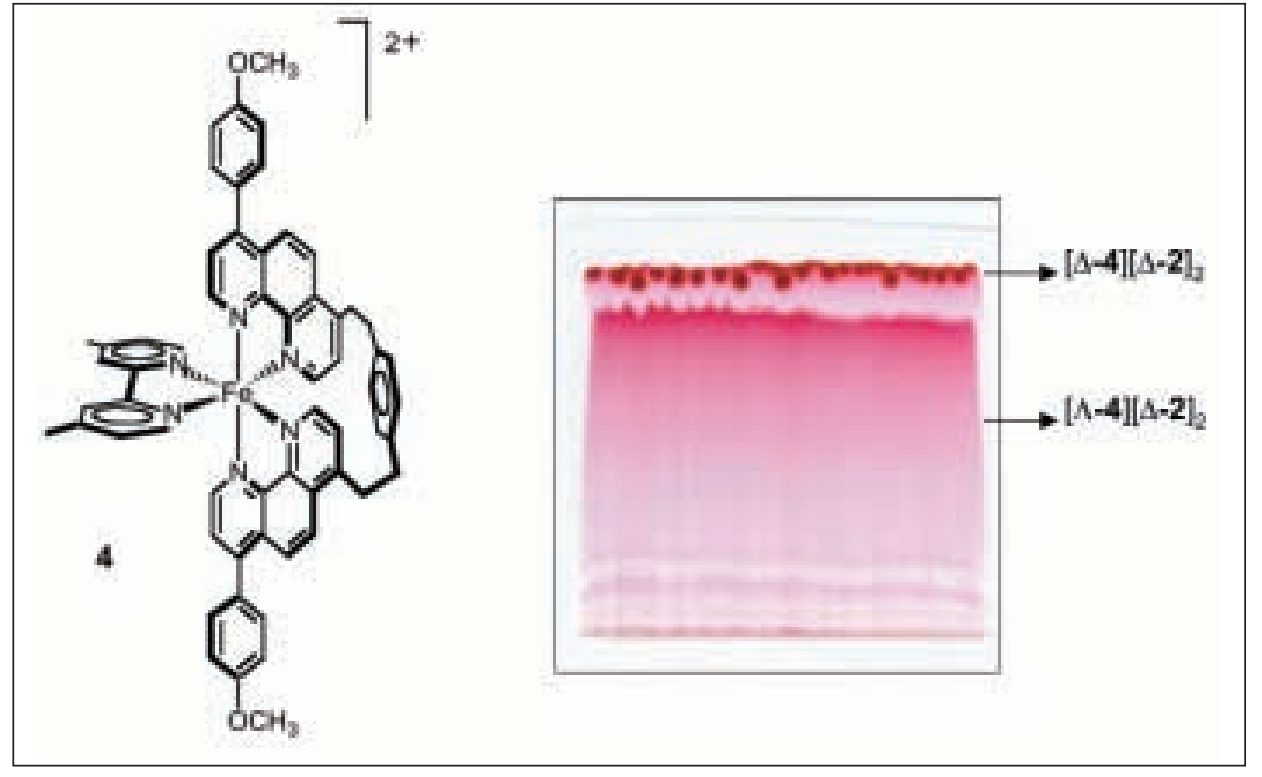

Iron(II) tris(diimine) complexes [31], dicobalt(II) helicates [32], monomethine dyes [8] and diquat cations [13] were studied in conjunction with anions $\mathbf{2}$ and $\mathbf{3}$ (Fig. 5). As desired, the NMR signals of the chiral cations were split by the presence of the anions and diastereomeric ratios as high 49:1 were observed for some of the substrates (Fig. 6, d.r. 10:1).

Recently, in collaboration with the group of Jean-Pierre Sauvage (University Louis Pasteur, Strasbourg), the asymmetryinducing properties of $\mathbf{2}$ were used to synthesize a configurationally stable iron(II) complex 4 (Fig. 4) as a single diastereomer [27].

\section{Acknowledgments}

I am much indebted to the enthusiastic efforts of all the former and present members of the group who have contributed to the success of
Fig. 4. Ion pair chromatographic resolution of configurationally stable iron(II) complex 4.<smiles></smiles>

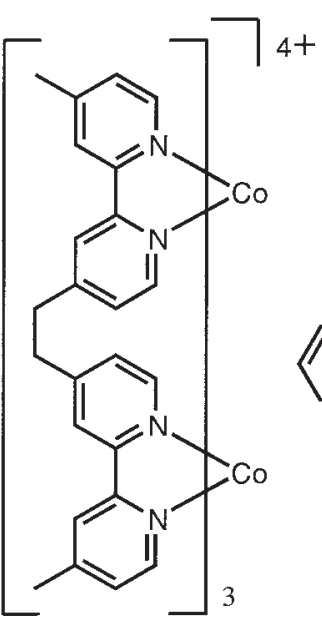

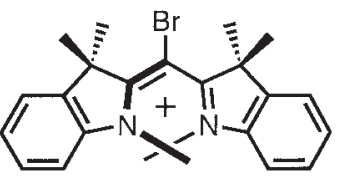<smiles>[R]c1cc[n+]2c(c1)-c1cc([R])cc[n+]1CCC2</smiles>

Fig. 5. Configurationally labile cations studied in conjunction with anions 2 or $\mathbf{3}$. 


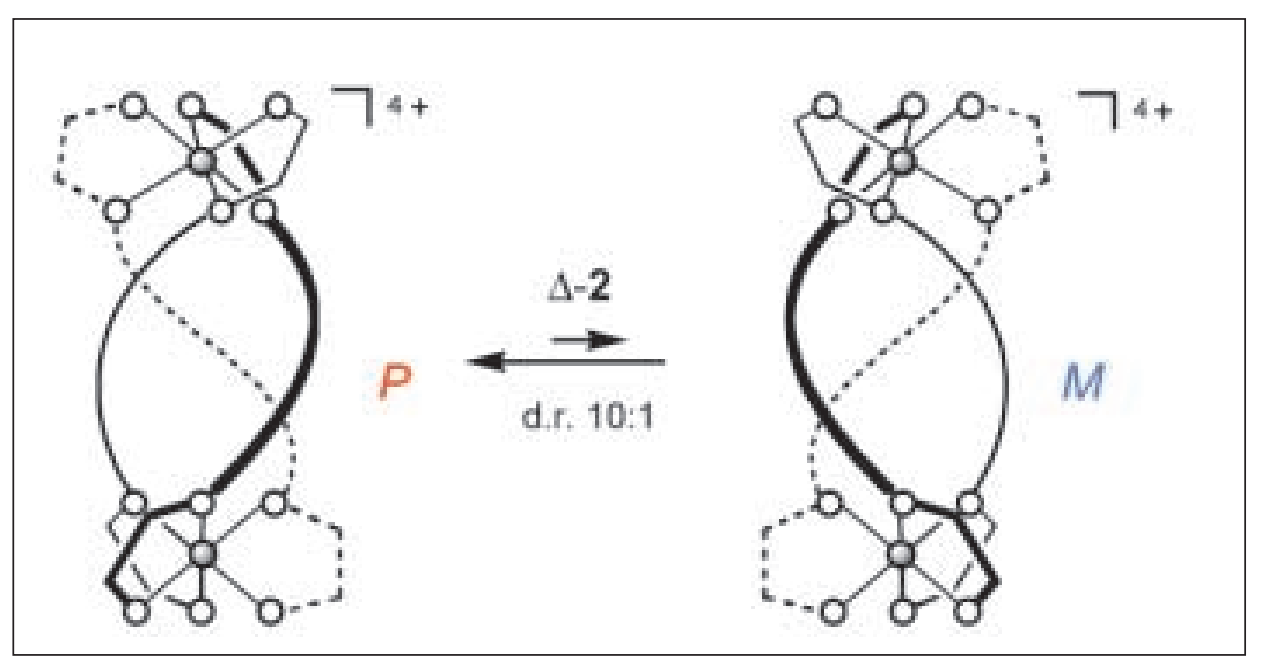

our projects. Particularly involved in what has been reviewed here are Samuel Constant, Valérie Desvergnes-Breuil, France Favarger, Catherine Goujon-Ginglinger, Virginie Hebbe, Christelle Herse, Jonathan J. Jodry, Anne Londez, David Monchaud, Sonya TorcheHaldimann, Duy-Hien Tran and Laurent Vial. We all are grateful for financial support of this work by the Swiss National Science Foundation, the Federal Office for Education and Science (COST D11), the Société Académique de Genève, the Schmidheiny Foundation as well as the Sandoz Family Foundation.

Received: September 26, 2002

[1] D.F. Duxbury, Chem. Rev. 1993, 93, 381.

[2] J.F. Stoddart, Acc. Chem. Res. 2001, 34, 410; V. Amendola, L. Fabbrizzi, C. Mangano, P. Pallavicini, Acc. Chem. Res. 2001, 34, 488; R. Ballardini, V. Balzani, A. Credi, M.T. Gandolfi, M. Venturi, Acc. Chem. Res. 2001, 34, 445; J.-P. Collin, C. Dietrich-Buchecker, P. Gavina, M.C. Jimenez-Molero, J.-P. Sauvage, Acc. Chem. Res. 2001, 34, 477; J.-P. Sauvage, Science 2001, 291, 2105.

[3] (a) D. Owen, G.B. Schuster, J. Am. Chem. Soc. 1996, 118, 259; (b) D.J. Owen, D. VanDerveer, G.B. Schuster, J. Am. Chem. Soc. 1998, 120, 1705; (c) S. Green, A. Nelson, S. Warriner, B. Whittaker, J. Chem. Soc, Perkin Trans. 1 2000, 4403; (d) D.B. Llewellyn, D. Adamson, B.A. Arndtsen, Org. Lett. 2000, 2, 4165.

[4] M. Koenig, A. Klaebe, A. Munoz, R. Wolf, J. Chem. Soc., Perkin Trans. 2 1976, 955; A. Klaebe, M. Koenig, R. Wolf, P. Ahlberg, J. Chem. Soc., Dalton Trans. 1977, 570; J. Cavezzan, G. EtemadMoghadam, M. Koenig, A. Klaebe, Tetrahedron Lett. 1979, 795; M. Koenig, A. Klaebe, A. Munoz, R. Wolf, J. Chem. Soc., Perkin Trans. 2 1979, 40.

[5] J. Lacour, C. Ginglinger, C. Grivet, G. Bernardinelli, Angew. Chem. Int. Ed. Engl. 1997, 36, 608.

[6] (a) J. Lacour, C. Ginglinger, F. Favarger, S. Torche-Haldimann, Chem. Commun.
1997, 2285. (b) J. Lacour, C. Ginglinger, F. Favarger, Tetrahedron Lett. 1998, 4825.

[7] J.K. Whitesell, Chem. Rev. 1989, 89, 1581; A. Alexakis, P. Mangeney, Tetrahedron: Asymmetry 1990, 1, 477.

[8] J. Lacour, A. Londez, C. Goujon-Ginglinger, V. Buß, G. Bernardinelli, Org. Lett. 2000, 2, 4185.

[9] J. Lacour, A. Londez, J. Organomet. Chem. 2002, 643-644, 392.

[10] J. Lacour, A. Londez, D.-H. Tran, V. Desvergnes-Breuil, S. Constant, G. Bernardinelli, Helv. Chim. Acta 2002, 85, 1364.

[11] D. Parker, Chem. Rev. 1991, 91, 1441.

[12] R.E. Graves, P.I. Rose, J. Chem. Soc., Chem. Commun. 1973, 630; J.K. Barton, J.S. Nowick, J. Chem. Soc., Chem. Commun. 1984, 1650; T.J. Wenzel, J. Zaia, $J$. Org. Chem. 1985, 50, 1322; T.J. Wenzel, C.A. Morin, A.A. Brechting, J. Org. Chem. 1992, 57, 3594; T.K. Green, J.R. Whetstine, E.J.R. Son, Tetrahedron: Asymmetry 1997, 8, 3175; L.H. Uppadine, F.R. Keene, P.D. Beer, J. Chem. Soc. Dalton Trans. 2001, 2188.

[13] C. Pasquini, V. Desvergnes-Breuil, J.J. Jodry, A. Dalla Cort, J. Lacour, Tetrahedron Lett. 2002, 43, 423.

[14] J. Lacour, L. Vial, C. Herse, Org. Lett. 2002, 4, 1351

[15] C. Ginglinger, D. Jeannerat, J. Lacour, S. Jugé, J. Uziel, Tetrahedron Lett. 1998, 39 , 7495.

[16] L. Pasquato, C. Herse, J. Lacour, Tetrahedron Lett. 2002, 43, 5517.

[17] O. Maury, J. Lacour, H. Le Bozec, Eur. J. Inorg. Chem. 2001, 201.

[18] J. Giner Planas, D. Prim, F. Rose-Munch, E. Rose, D. Monchaud, J. Lacour, Organometallics 2001, 20, 4107.

[19] H. Amouri, R. Thouvenot, M. Gruselle, B. Malezieux, J. Vaissermann, Organometallics 2001, 20, 1904; H. Mesnil, M.C. Schanne-Klein, F. Hache, M. Alexandre, G. Lemercier, C. Andraud, Chem. Phys. Lett. 2001, 338, 269. M. Brissard, M. Gruselle, B. Malezieux, R. Thouvenot, C. Guyard-Duhayon, O. Convert, Eur. J. Inorg. Chem. 2001, 1745; M. Brissard, H. Amouri, M. Gruselle, R. Thouvenot, Comptes Rendus Chimie 2002, 5, 53.
Fig. 6. Asymmetric induction by TRISPHAT 2 onto a dicobalt(II) triple stranded helicate.
[20] H. Ratni, J.J. Jodry, J. Lacour, E.P Kündig, Organometallics 2000, 19, 3997.

[21] E.L. Eliel, S.H. Wilen, 'Stereochemistry of Organic Compounds', John Wiley \& Sons, New York, 1994 pp. 416. RC. Helgeson, J.M. Timko, P. Moreau, S.C. Peacock, J.M. Mayer, D.J. Cram, J. Am. Chem. Soc. 1974, 96, 6762; V. Prelog, Z. Stojanac, K. Kovacevic, Helv. Chim. Acta 1982, 65, 377. M.V. Martínez-Díaz, J. de Mendoza, T. Torres, Tetrahedron Lett. 1994, 35, 7669; V. Andrisano, G. Gottarelli, S. Masiero, E.H. Heijne, S. Pieraccini, G.P. Spada, Angew. Chem. Int. Ed. 1999, 38, 2386.

[22] J. Lacour, C. Goujon-Ginglinger, S. Torche-Haldimann, J.J. Jodry, Angew. Chem. Int. Ed. 2000, 39, 3695.

[23] J.J. Jodry, J. Lacour, Chem. Eur. J. 2000, 6, 4297.

[24] J. Lacour, S. Barchéchath, J.J. Jodry, C. Ginglinger, Tetrahedron Lett. 1998, 39 , 567.

[25] J. Lacour, S. Torche-Haldimann, J.J. Jodry, C. Ginglinger, F. Favarger, Chem. Commun. 1998, 1733.

[26] D. Monchaud, J. Lacour, C. Coudret, S. Fraysse, J. Organomet. Chem. 2001, 624, 388.

[27] D. Monchaud, J.J. Jodry, D. Pomeranc, V. Heitz, J.-C. Chambron, J.-P. Sauvage, J. Lacour, Angew. Chem. Int. Ed. 2002, 43, 2317.

[28] A. von Zelewsky, Coord. Chem. Rev. 1999, 190-192, 811; A. von Zelewsky, O. Mamula, J. Chem. Soc., Dalton Trans. 2000, 219.

[29] P. Pfeiffer, K. Quehl, Chem. Ber 1931, 64, 2667; M.M. Green, C. Khatri, N.C. Peterson, J. Am. Chem. Soc. 1993, 115, 4941; R.M. Yeh, M. Ziegler, D.W. Johnson, A.J. Terpin, K.N. Raymond, Inorg. Chem. 2001, 40, 2216.

[30] S. Kirschner, N. Ahmad, C. Munir, R.J. Pollock, Pure Appl. Chem. 1979, 51, 913; B. Norden, F. Tjerneld, FEBS Lett. 1976, 67, 368 .

[31] J. Lacour, J.J. Jodry, C. Ginglinger, S. Torche-Haldimann, Angew. Chem. Int. Ed. Engl. 1998, 37, 2379.

[32] J. Lacour, J.J. Jodry, D. Monchaud, Chem. Commun. 2001, 2302. 